\title{
Comparison of infrared thermography and miniature Deltatron accelerometer sensors in the measurement of structural vibration characteristics
}

\author{
Stephen M. Talai ${ }^{1 *}$, Dawood A. Desai ${ }^{1}$ and P. Stephan Heyns ${ }^{2}$ \\ ${ }^{1}$ Department of Mechanical Engineering, Tshwane University of Technology, Pretoria, South Africa \\ ${ }^{2}$ Department of Mechanical and Aeronautical Engineering, University of Pretoria, Hartfield, South Africa \\ *Corresponding author email: stevetalai@gmail.com; TalaiSM@tut.ac.za
}

\begin{abstract}
This paper investigates the comparison of infrared thermography (IRT) and miniature Deltatron accelerometer sensors in measuring structural vibration characteristics in terms of frequency and displacement, given that of age IRT has fully grown for temperature condition monitoring. In addition, IRT has been extensively applied in non-destructive techniques for evaluation of surface cracks through the observation of thermal imaging of vibration-induced crack frictional heat generation. Therefore, in order to conduct this study, both single and dual cantilever beam-like structures (AISI 304 steel) coupled with a slipping frictional rod (lacing wire) were subjected to forced excitations with an infrared camera capturing the thermal profile emanating from beam-lacing wire frictional interface. Concurrently, miniature Deltatron accelerometer sensors were attached to the beam surface next to the frictional interface focused by IR camera. The thermally analyst vibration characteristics parameters were compared against those acquired by accelerometers. The comparison of results exhibited a maximum relative difference of $0.28 \%$ and $14.88 \%$ for frequencies and displacements, respectively. This shows that IRT is more reliable in measuring structural vibration frequency than displacements. The finding is particularly useful in overcoming many limitations inherent in some of the current vibration measuring techniques such strain gauges failure due to fatigue.
\end{abstract}

Keywords: condition monitoring, structural health monitoring, frictional temperature evolution, online monitoring

\section{Introduction}

In today's mechanical and aerospace engineering communities, the need for enhanced ability to monitor dynamic structures and detect potential damages at the earliest possible stage for effective structural health monitoring (SHM) is ever increasing (Le et al. 2016). The available literature indicates that condition monitoring of vibrating structures has been an active area of research since 1950s when Arthur Crawford first acknowledged the challenge to acquire an effective way to analyze structural vibration.

For decades, however, vibration monitoring has been utilized to assess SHM in predicting potential failures that, in turn, enhance the reliability and availability of dynamic components such as steam turbine blades (Rao 1991; Mukhopadhyay et al. 1998). The direct methods of measurements such as accelerometers and strain gauges have predominantly been used. Although they have the advantage of performing measurement of an individual structure, they have several disadvantages such as shorter sensor life spans due to continued cyclic loading, leading to failure by fatigue (Al-Bedoor 2002). Laser Doppler vibrometry with an Eulerian approach allows overcoming most of the limitations mentioned in the use of strain gauges. Nevertheless, Castellini, Martarelli, and Tomasini (2006) reported that its main limitations are speckle effects and poor signal-to-noise ratio when measuring vibration on the low diffusive surface. Also, Interferometry method has the ability to provide traceability of vibration frequency measurement as it relates directly to the definition of the metre. Its measurement accuracy, however, is limited by the environment (Brock et al. 2005); thus, it is not be possible to perform the vibration measurement in a turbulent environment, for instance power plants.

Of age, infrared thermography (IRT) has been extensively applied to the vibrothermography non-destructive technique where surface cracks are evaluated through the observation of thermal imaging of vibration-induced heat generation. Recent studies have shown that defect heating in cracked metallic structures is primarily generated by frictional rubbing on crack faces (Renshaw et al. 2011). Mabrouki et al. (2009) investigated the vibrothermography for detection of fatigue cracks in steel compact tension specimens. Lahiri et al. (2014) proposed the active IRT-based technique for detecting defects in ferromagnetic specimens using low frequency alternating magnetic field induced heating. Using an infrared camera, the authors observed an increase in the surface temperature due to induced eddy current leading to joules heating. Furthermore, Montanini and Freni (2013) established that there exists a correlation of vibrational mode shape to viscoelastic heat generation in vibrothermography.

However, friction is often considered by engineers as detrimental to the design of dynamic mechanisms involving mating parts. Despite this, it has long been established that it can as well provide a very effective means of dissipating vibratory energy in elastic structures. This technique is used in applications such as turbomachinery bladed disks (Mukhopadhyay et al. 1998; Singh and Lucas 2011), where either the lacing wire is incorporated at the chosen location of the blade structure or direct interaction of the constitutive blades through the shrouded tip approach for enhancing passive dissipation of vibratory energy. In reality, it is often structural joints that are more responsible for energy dissipation than the (solid) material itself (Guran, Pfeiffer, and Popp 2001; Straffelini 2015). Ultimately, this leads to a temperature increase at the contact interface (Dimarogonas, Paipetis, and Chondros 2013). Hence, analysis of frictional heat generation due to interacting components can result in 
a quick and reliable indication of the structural vibration characteristics.

Accordingly, despite the large amount of research conducted on condition monitoring using IRT as indicated in the recent comprehensive literature review by Bagavathiappan et al. (2013), little research attention has been paid to vibration measurement.

Therefore, this it was the aim of this paper to compare experimentally IRT and accelerometers in the vibration characteristics measurement in terms of frequency and displacement. In order to achieve this, both single and dual cantilever beam-like structures (AISI 304 steel) coupled with a lacing slipping frictional rod (lacing wire) were subjected to forced excitations with an infrared camera capturing the thermal profile emanating from the beam-lacing wire frictional interface. Concurrently, miniature Deltatron accelerometer sensors were attached to the beam surface next to the frictional interface focused by IR camera. An electrodynamic shaker attached to the beam vie stinger provided the mechanical excitation. The methodology developed forms the basis for online structural health monitoring (SHM) employing IRT. Its benefit to the maintenance is the online SHM, most importantly, in harsh and turbulent environments.

\section{Mathematical model \\ Vibration frequencies}

The post analysis of thermal imaging data yields the temperature time-domain waveform. It does not seem, by eye, to have any underlying sinusoidal signal components; instead, it seems completely random and consisting of noise. However, the Discrete Fourier Transform (DFT) analysis is utilized to check for the spectral peak. The DFT for a sequence, $x(n T)$, is given by

$$
X(k F)=\sum_{n=0}^{N-1} x(n T) e^{-j 2 \pi F n t}
$$

where $\mathrm{N}$ is the number of samples, $\mathrm{F}$ is the spacing of frequency domain samples, $\mathrm{T}$ is the sample period in the time domain, and $k$ and $n$ are integers. The MATLAB Fast Fourier Transform (FFT) function performs computation of DFT in an efficient way. Therefore, considering the sampling frequency of an IR camera being used for SHM, and the frictional temperature time-domain waveform sequence as X, a Matlab FFT algorithm was developed as follows:

$$
\begin{aligned}
& F_{s}=f ; \\
& T=1 / F_{s} ; \\
& L=\text { length }(X) ; \\
& Y=f f t(X) ; \\
& P 2=a b s(Y / L) ; \\
& P 1=P 2(1: L / 2+1) ; \\
& P 1(2: \operatorname{end}-1)=2^{*} P \\
& f=F_{s}^{*}(0:(L / 2)) / L ; \\
& \operatorname{Plot}(f, P 1) ;
\end{aligned}
$$$$
P 1(2 \text { :end }-1)=2^{*} P 1(2 \text { :end }-1) ; \quad \% \text { FFT amplitude }
$$

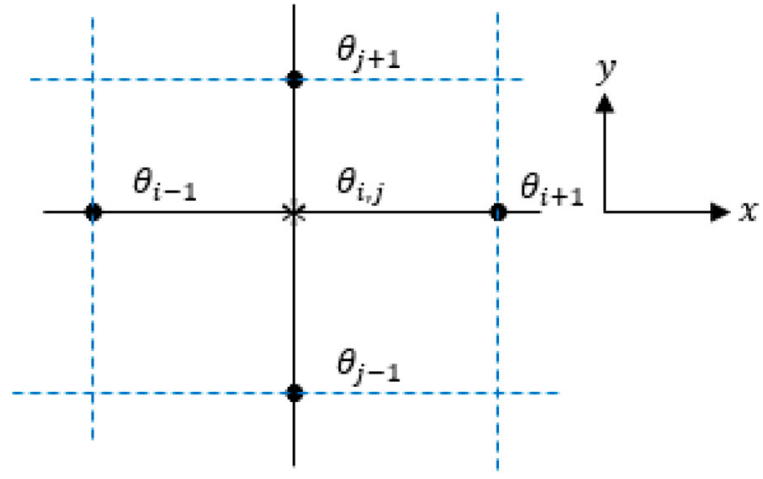

Figure 1: Finite surface temperature distribution grid.

\section{Correlation of beam transverse displacement to surface frictional temperature distribution}

The heat conduction equation for the Cartesian co-ordinate system $(x, y, z)$ on the beam surface differential element can be expressed as (Rajput 2006)

$$
\frac{\partial^{2} \theta}{\partial x^{2}}+\frac{\partial^{2} \theta}{\partial y^{2}}+\frac{\partial^{2} \theta}{\partial z^{2}}+\frac{q_{g}}{k}=\frac{1}{\alpha} \frac{\partial \theta}{\partial t}
$$

where $\theta$ is the temperature rise on the beam surface, $k$ is thermal conductivity, $\rho$ is the material density and $c$ is the specific heat capacity, $q_{g}$ is the heat generated per unit volume and $\alpha$ is the thermal diffusivity. The grid distribution technique as given in Figure 1 analyses the surface temperature.

Following the work of Talai, Desai, and Heyns (2016) in conjunction with Figure 1, the temperature rise finite difference equations for the grid in $\Delta x$ and $\Delta y$ are

$$
\begin{gathered}
\frac{\partial^{2} \theta}{\partial x^{2}}=\frac{1}{(\Delta x)^{2}}\left(\theta_{i+1}-2 \theta_{i, j}+\theta_{i-1}\right), \\
\frac{\partial^{2} \theta}{\partial y^{2}}=\frac{1}{(\Delta y)^{2}}\left(\theta_{j+1}-2 \theta_{i, j}+\theta_{j-1}\right)
\end{gathered}
$$

while the beam transverse displacement from the surface temperature distribution acquired using IRT is given as

$$
z(t)=\frac{k \sin (\omega t)}{2 \mu N \omega}\left[\frac{2 h_{c o n}}{c k} \theta_{i, j}-\frac{\partial^{2} \theta}{\partial x^{2}}-\frac{\partial^{2} \theta}{\partial y^{2}}\right]
$$

\section{Materials and Experimental Method Materials}

Both the beam and the lacing wire were manufactured of AISI 304 stainless steel due its low thermal conductivity, allowing it to generate heat with slight frictional effect (Mabrouki et al. 2009). The geometric and material properties are given in Table 1 and Table 2, respectively.

\section{Experimental procedure}

The laboratory experimental setup for a single cantilever beam structural analysis was as presented in Figure 2a. Before the beam excitation, the pre-load force of $2.25 \mathrm{~N}$ was applied to the lacing wire for the purpose of 
Table 1: Geometric dimensions.

\begin{tabular}{ll} 
Description & Parameters \\
\hline Beam mass & $0.10 \mathrm{~kg}$ \\
Beam length & $300 \mathrm{~mm}$ \\
Beam width & $25 \mathrm{~mm}$ \\
Beam thickness & $2 \mathrm{~mm}$ \\
Lacing wire diameter & $5 \mathrm{~mm}$ \\
Beam hole diameter & $5_{+0.412}^{+0.422} \mathrm{~mm}$ \\
[tolerance grade: $F 8 / j s 7$ ] (Sanders 1996) Beam- & \\
lacing wire hole location from fixed end Beam & $250 \mathrm{~mm}$ \\
exciters location from fixed end & $290 \mathrm{~mm}$
\end{tabular}

Table 2: AISI 304 material properties (Madhusudana 1999).

\begin{tabular}{ll} 
Structural properties & Parameters \\
\hline Density, $\rho$ & $7740 \mathrm{~kg} / \mathrm{m}^{3}$ \\
Young modulus, E & $200 \mathrm{GPa}$ \\
Poisson ratio, $v$ & 0.33 \\
Static friction coefficient, $\mu_{s}\left(\mu_{k}=0.75 \mu_{s}\right)$ & 0.15 \\
(Oden and Martins 1985) & \\
Thermal properties & \\
Thermal conductivity, $k$ & $16.5 \mathrm{~W} /$ \\
& $\mathrm{m} . \mathrm{K}$ \\
Specific heat capacity, $c$ & $500 \mathrm{~J} / \mathrm{kg} . \mathrm{K}$
\end{tabular}

uniformity. This was achieved by tightening of the adjusting bolt that pushed the lacing wire laterally via a sleeve, while a PCB force transducer model 208C02 with sensitivity rating of $11.24 \mathrm{mV} / \mathrm{N}$ measured the attained force. The forcing frequency signals obtained from the function generator (FG-7005C) were amplified (power amplifier model: LA-1500) before being transmitted to the electrodynamic exciter (Type: 4824, Brüel \& Kjor) to facilitate the beam forced excitation via a stinger coupled with a PCB force transducer model 208C04 with sensitivity rating of $1.124 \mathrm{mV} / \mathrm{N}$, to measure the output force. The excitation frequencies considered were $20 \mathrm{~Hz}$ and $50 \mathrm{~Hz}$. These were considered based on Shannon's sampling rate theorem of 0.4 times the rated optical resolution of the IR camera used in this study. Concurrently, a Micro-epsilon (TIM160) infrared camera focused on the beam-lacing wire interface to capture the thermal image. It has a thermal sensitivity of $0.08 \mathrm{~K}$, a spectral range of $7.5-13 \mu \mathrm{m}$, an optical resolution of $160 \times 120$ pixels, and a frame rate real time of $120 \mathrm{~Hz}$.

In the case of structural vibration analysis for the dual cantilever beam, the experimental setup as used in the work of Talai, Desai, and Heyns (2016) was utilized in this study and the schematic representation in given Figure $2 \mathrm{~b}$. The pre-load force of $15 \mathrm{~N}$ was applied at the lacing wire throughout the experiments. Three excitation patterns of the beams were considered. Firstly; both beams at the same forcing frequency of $20 \mathrm{~Hz}$ and, secondly, beam 1 at $40 \mathrm{~Hz}$ and beam 2 at $20 \mathrm{~Hz}$.

These excitation frequencies were considered based on Shannon's sampling rate theorem of 0.4 times the rated optical resolution of the IR cameras used. The thermal imaging considered $150 \mathrm{~s}$ recording time as required by the operation manual for the reliable real time temperature recording (full pixel recording). This short time duration goes a long way in avoiding the effect of significant wear rate at the friction interface during excitation. In order to check the comparison of IRT for vibration measurement, the corresponding parameters were compared against those acquired by the miniature Deltatron accelerometers.

In the case of the single cantilever beam, a miniature Deltatron accelerometer type 4507 with the sensitivity rating of $97.96 \mathrm{mV} / \mathrm{g}$ and a mass of $4.8 \mathrm{~g}$ (Brüel \& Kjorr) was mounted to the surface using beeswax. The RT pro Photon FFT analyser (Brüel \& Kjorr) then acquired the dynamic measurements. However, for the dual cantilever beam vibration analysis, the described miniature Deltatron accelerometers in the work of Talai, Desai, and Heyns (2016) were adopted.

The problem of low thermal emissivity of the beam surface was eliminated by applying black paint which is consistent with standard practice in this field (Mabrouki et al. 2009).

\section{Results and discussions \\ Single cantilever beam analysis at excitation of $20 \mathrm{~Hz}$ and $50 \mathrm{~Hz}$}

During this particular analysis, the ambient room temperature recorded was $22.4^{\circ} \mathrm{C}$. The acquired images with the grid interface temperature distributions emanating from these frequencies are given in Figure 3, while the MATLAB detrended frictional temperature evolution wave-form corresponding to the hottest interface is shown in Figure 4.

As expected, the structure under higher excitation frequency allows the frictional interfaces to slide against each other more times, unlike at lower frequencies, leading to greater frictional heat generation as seen by the temperature difference of $1.2^{\circ} \mathrm{C}$ among the images. The developed MATLAB FFT algorithm was utilized to transform the frictional temperature evolution time history (Figure 4) into the frequency domain as shown in Figure 5. The vibration frequencies correspond to the longest peak of the spectrum and, hence, extracted as $20.0059 \mathrm{~Hz}$ (Figure 5a) and $50.0015 \mathrm{~Hz}$ (Figure 5b) for the beam forcing frequencies of 20 and $50 \mathrm{~Hz}$, respectively.

The resultant frictional force acting on lacing wire was computed based on the representation given in Figure 6.

where, $F_{f}=\sqrt{\left(F_{m}^{2}+P^{2}\right)}, F_{m}$ is the maximum exciter force and $P$ is the pre-load force. Therefore, the interface frictional force corresponding to the excitation frequencies of $20 \mathrm{~Hz}$ and $50 \mathrm{~Hz}$ were $5.974 \mathrm{~N}$ and $6.826 \mathrm{~N}$, respectively.

The beam displacements were analyzed using the finite element approach proposed in Figure 1 in conjunc-tion with the interfacial temperature distribution in Figure 3. In the case of $20 \mathrm{~Hz}$ (Figure 3a), the finite nodal temperature using Equation 3 along $X$ and $Y$ direc-tions were $-1.3^{\circ} \mathrm{C} /$ $\mathrm{mm}^{2}$ and $0.00^{\circ} \mathrm{C} / \mathrm{mm}^{2}$, respectively. From Equation 4, the IRT predicted displacement was computed as $2.239 \mathrm{~mm}$. Similarly, in the case of $50 \mathrm{~Hz}$ (Figure 3b), the finite nodal temperatures along $X$ and $Y$ directions were $-0.9^{\circ} \mathrm{C} / \mathrm{mm}^{2}$ and $0.7^{\circ} \mathrm{C} / \mathrm{mm}^{2}$, respect-ively; while the displacement using Equation 4 was obtained as $0.877 \mathrm{~mm}$. The higher displacement at $20 \mathrm{~Hz}$ compared with that at 


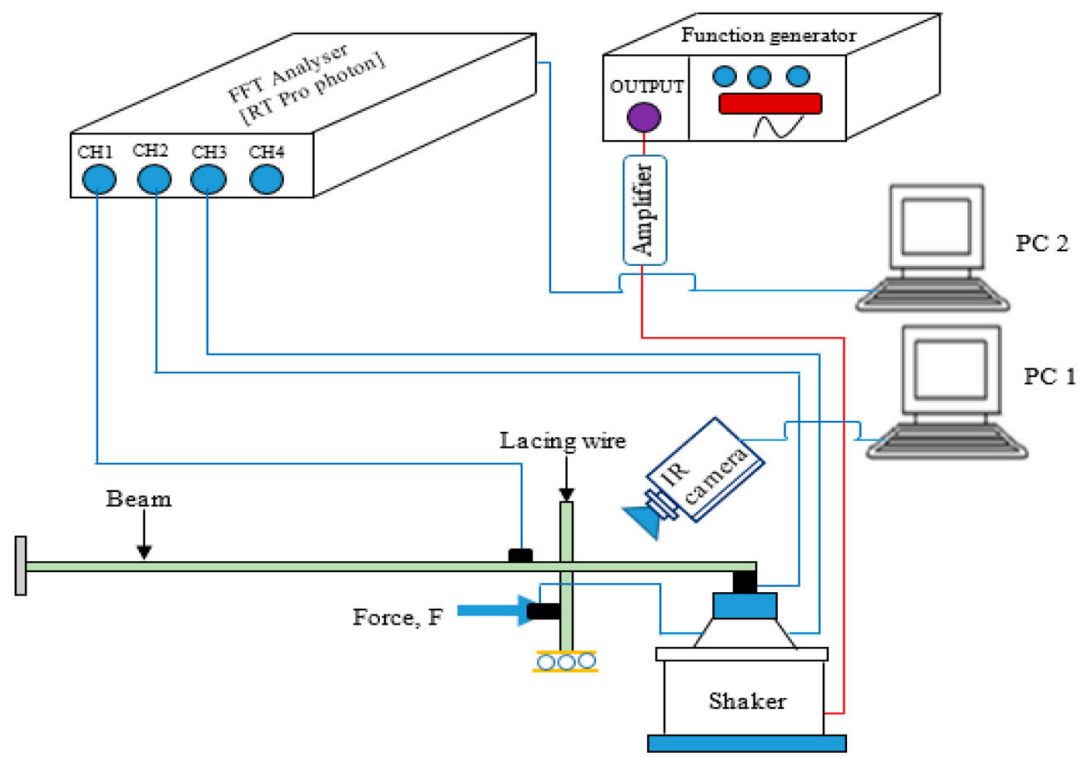

(a)

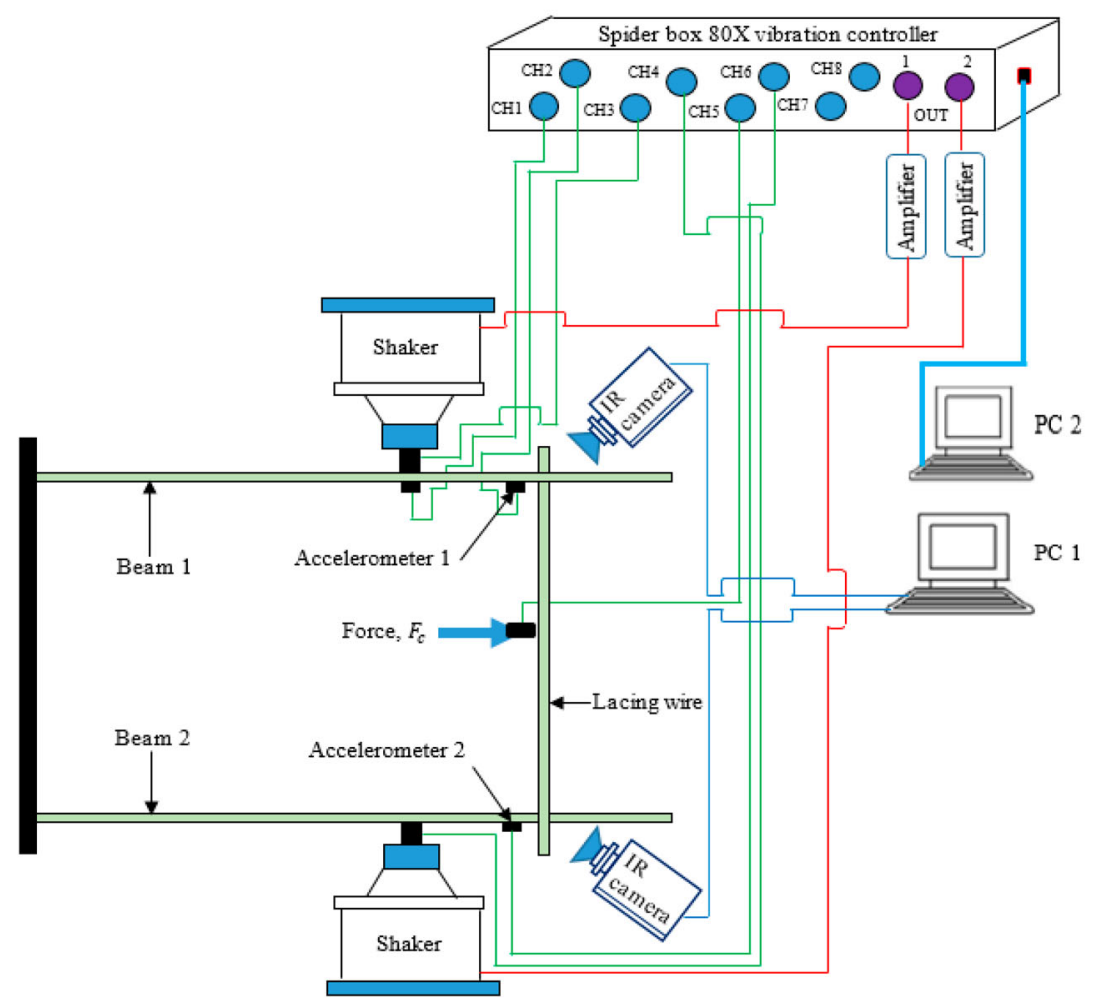

(b)

Figure 2: Laboratory experimental setup for vibration measurement using both IRT and miniature accelerometer for (a) single cantilever beam (b) dual cantilever beam.

Source: Talai, Desai, and Heyns 2016

$50 \mathrm{~Hz}$ justifies the larger temperature range variation for the former than the latter as depicted in Figure 5.

However, based on the described accelerometer, the beam vibration frequencies were extracted as $20.0196 \mathrm{~Hz}$ and $50.049 \mathrm{~Hz}$ for 20 and $50 \mathrm{~Hz}$ forcing frequencies, respectively (Figure 7). These compared quite well with those acquired using IRT approach with relative errors being $0.07 \%$ and $0.09 \%$ for the former and latter, respectively. Further, the beam displacement spatial statistics was as shown in Table 3, the mean being $2.108 \mathrm{~mm}$ and $0.912 \mathrm{~mm}$ for the forcing frequencies of $20 \mathrm{~Hz}$ and $50 \mathrm{~Hz}$, respectively. These exhibited the relative difference of $5.85 \%$ and $3.98 \%$ for the former and latter. The differences were attributed to partly location of accelerometer towards the beam fixed end and use of coefficient of fric-tion as well as convective heat losses from the literature that may not be the real values as per the experimental setup. 


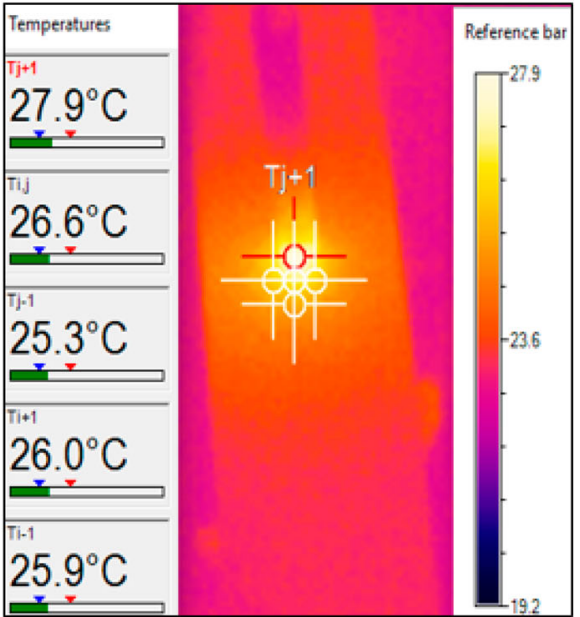

(a)

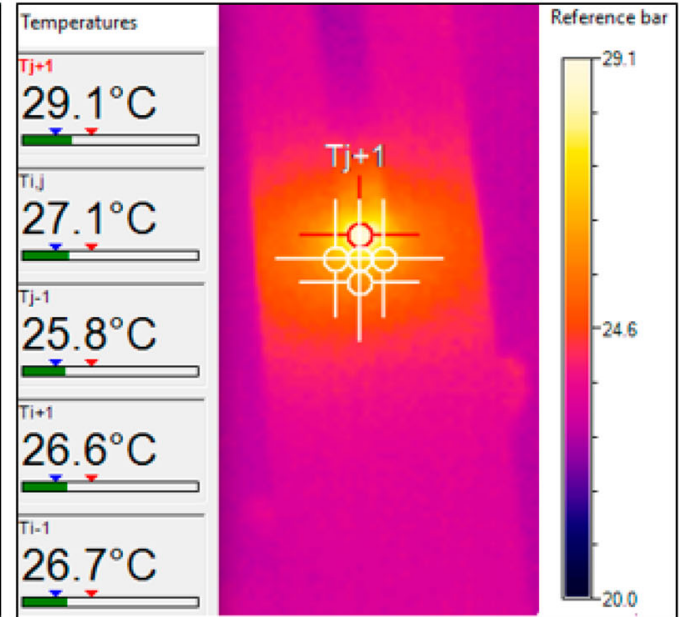

(b)

Figure 3: IR thermal images for the forcing frequency (a) $20 \mathrm{~Hz}$ and (b) $50 \mathrm{~Hz}$.

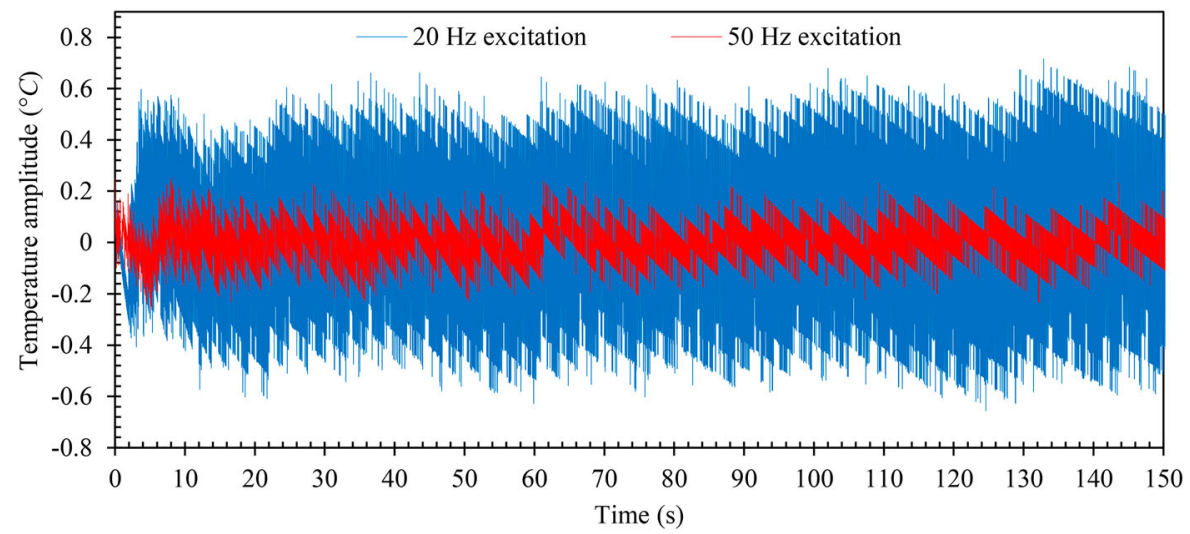

Figure 4: Frictional temperature evolution.

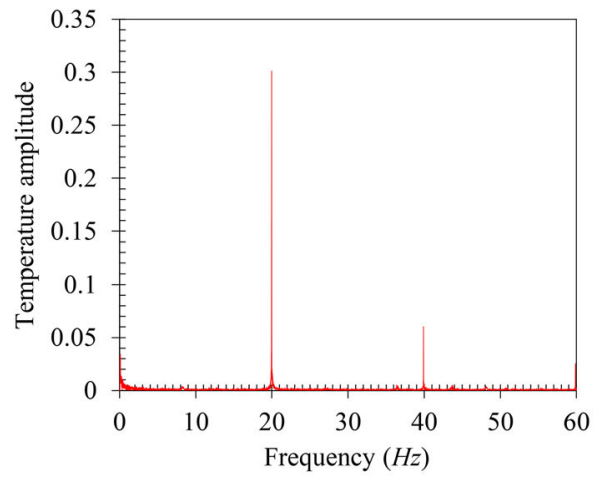

(a)

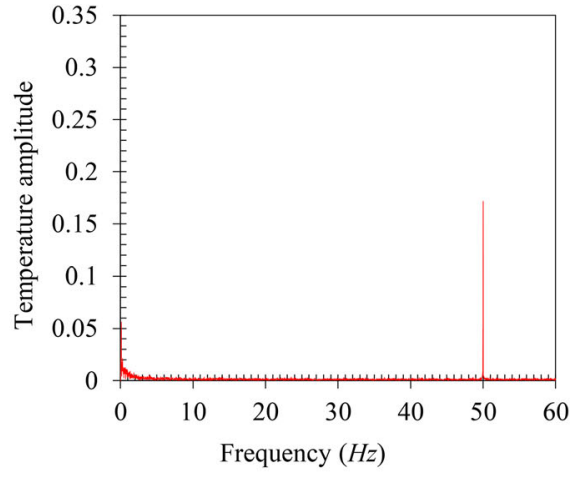

(b)

Figure 5: FFT of temperature evolution for beam excitation (a) at $20 \mathrm{~Hz}$ and (b) at $50 \mathrm{~Hz}$.

\section{Dual beam vibration analysis with excitation of $20 \mathrm{~Hz}$}

From the thermal imaging given in Figure 8, the analyzed structural frequencies were $19.9885 \mathrm{~Hz}$ (Figure 9a) and $19.9973 \mathrm{~Hz}$ (Figure 9b) for Beam 1 and 2, respectively. Further, Beam 1 possessed several smaller frequencies that were associate with the beam multi-dynamics emanating from the periodic loading.

In order to analytically determine the displacements as proposed, the beam-lacing wire interface frictional force was analytically computed as described in Figure 6. The

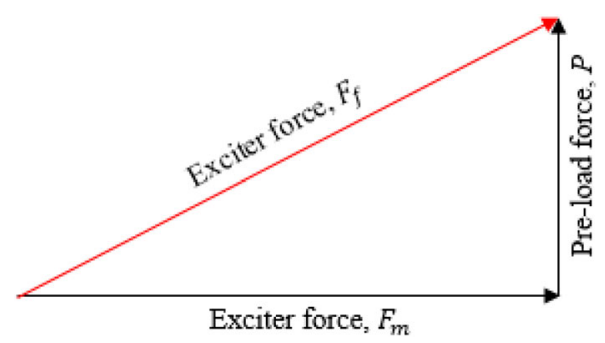

Figure 6: Beam-lacing wire interface force components. 


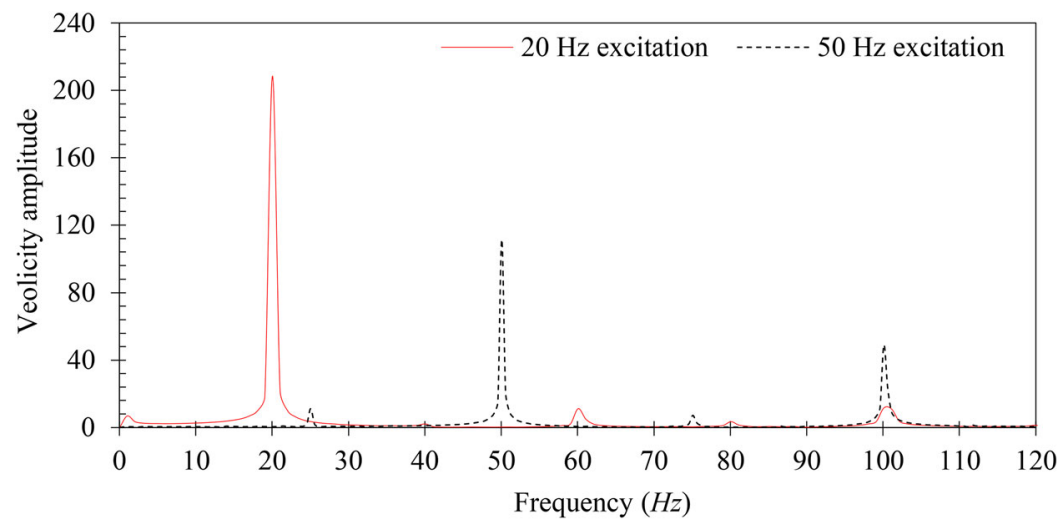

Figure 7: Beam FFT of velocity response.

Table 3: Single beam accelerometer measured displacement and exciter force statistics.

\begin{tabular}{|c|c|c|c|c|}
\hline \multirow[b]{2}{*}{ Description } & \multicolumn{2}{|c|}{$20 \mathrm{~Hz}$ forcing frequency } & \multicolumn{2}{|c|}{$50 \mathrm{~Hz}$ forcing frequency } \\
\hline & Disp. $(\mathrm{mm})$ & Exciter force $(N)$ & Disp. $(\mathrm{mm})$ & Exciter force $(N)$ \\
\hline Mean & 2.108 & 2.564 & 0.912 & 2.798 \\
\hline Max & 6.303 & 5.535 & 2.002 & 6.444 \\
\hline Min & 0.010 & 0.002 & 0.025 & 0.041 \\
\hline Range & 6.293 & 5.533 & 1.977 & 6.404 \\
\hline Std. deviation & 2.015 & 1.626 & 0.619 & 1.620 \\
\hline
\end{tabular}

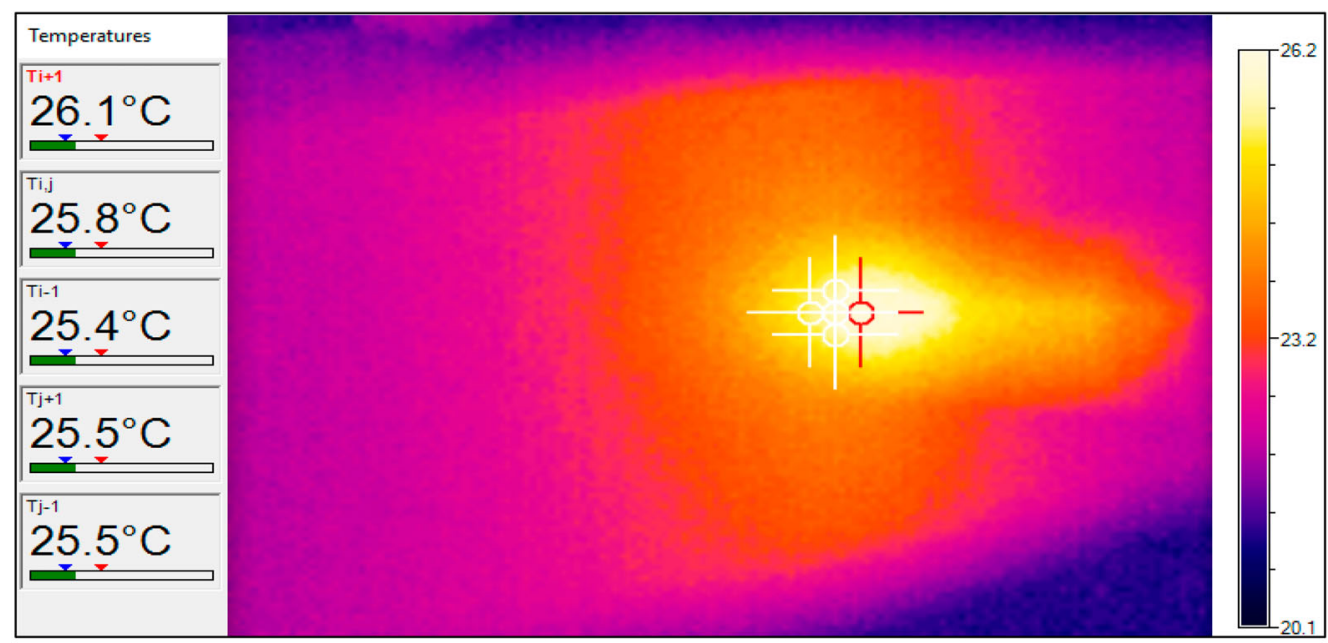

(a)

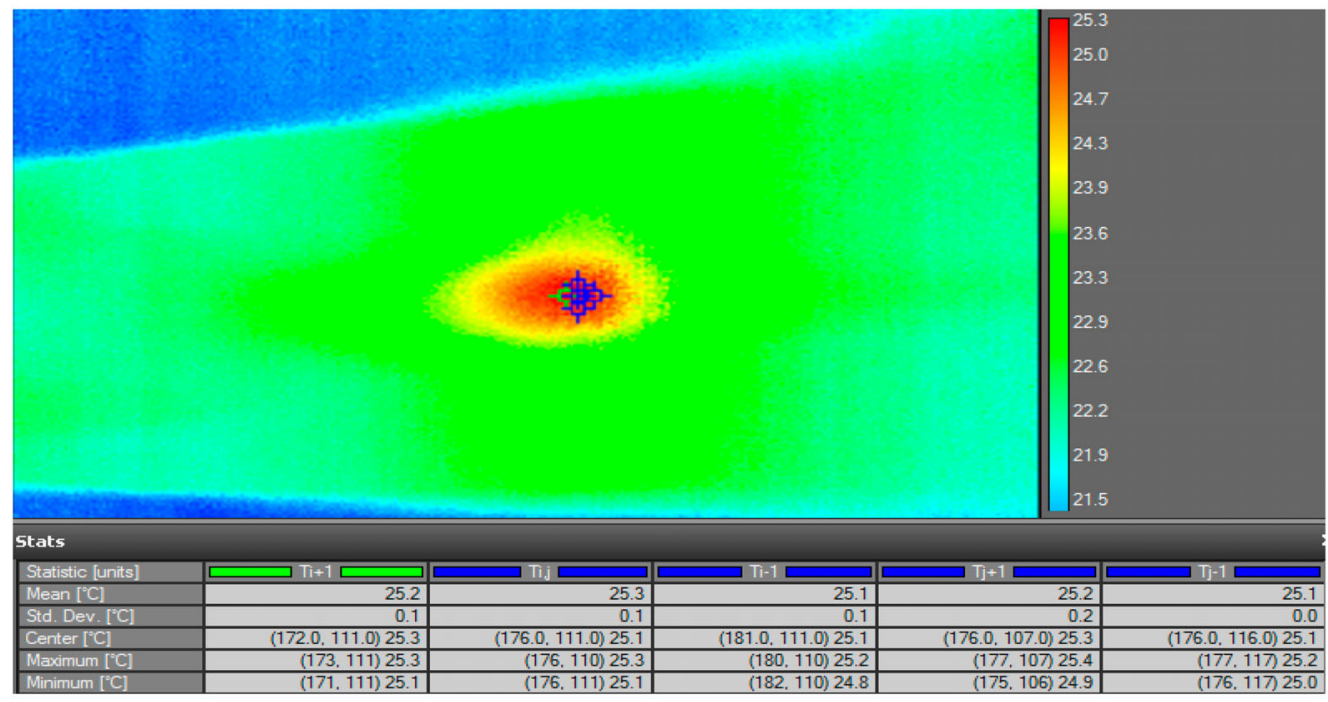

(b)

Figure 8: Thermal images after $150 \mathrm{~s}$ for both beams excited at $20 \mathrm{~Hz}$ (a) Beam 1 and (b) Beam 2 . 


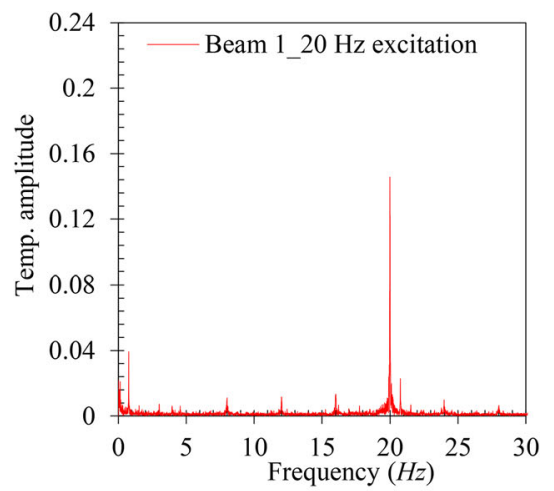

(a)

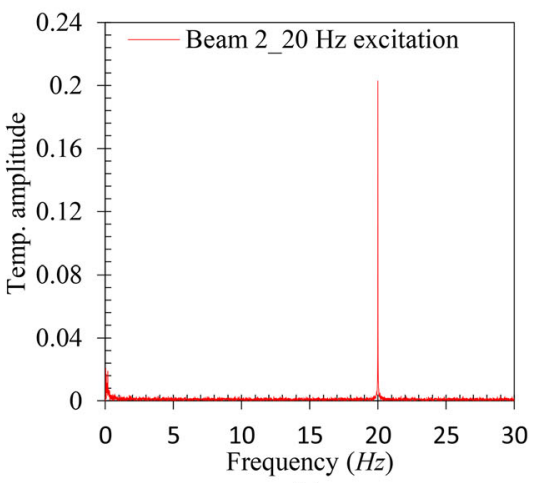

(b)

Figure 9: FFT of temperature evolution for both beams excited at $20 \mathrm{~Hz}$ (a) Beam 1 and (b) Beam 2.

mean excitation force was extracted from Table 4. Taking into consideration the pre-load force, the sliding interface frictional forces were computed as $7.91 \mathrm{~N}$ and $8.28 \mathrm{~N}$ for Beam 1 and Beam 2, respectively. Thus, in the analysis of displacement based on the thermal imaging for Beam 1 (Figure 8a), the interface finite temperature along the $X$ direction was obtained as $-0.1{ }^{\circ} \mathrm{C} / \mathrm{mm}^{2}$, along the $Y$ direction as $-0.6^{\circ} \mathrm{C} / \mathrm{mm}^{2}$ and the transverse displacement as $1.369^{\circ} \mathrm{C} / \mathrm{mm}$.

Likewise, in the case of Beam 2 (Figure 8b); the finite temperature along the $X$ direction evaluated as $-0.3^{\circ} \mathrm{C} /$ $\mathrm{mm}^{2}$, along the $Y$ direction as $-0.3^{\circ} \mathrm{C} / \mathrm{mm}^{2}$ and the transverse displacement obtained as $1.115 \mathrm{~mm}$.

The accelerometer sensor measured response showed both beams oscillated at $20.0401 \mathrm{~Hz}$ (Figure 10). These were in good agreement with those measured using IRT (Figure 9) with the relative difference being $0.26 \%$ and $0.21 \%$ for Beam 1 and Beam 2, respectively. The displacement statistics given in Table 4 indicate Beam 1 oscillated with greater variation as seen with the large standard deviation that was attributed to the dynamics emanating from the excitations of the beams. Compared with the IRT measured displacements, the accelerometer mean displacement (Table 4) exhibited the relative differences of $13.36 \%$ and $8.81 \%$ for Beam 1 and Beam 2, respectively.

\section{Dual beam vibration analysis with excitation of Beam 1 at $40 \mathrm{~Hz}$ and Beam 2 at $20 \mathrm{~Hz}$}

The frequencies analyzed from thermal images shown in Figure 11 were $39.9686 \mathrm{~Hz}$ (Figure 12a) and $20.0000 \mathrm{~Hz}$ (Figure 12b) for Beam 1 and Beam 2, respectively. By following a similar approach as discussed in conjunction with the mean shaker force from Table 5, the beam- lacing wire interface frictional forces were analyzed as 13.50 $\mathrm{N}$ and $11.16 \mathrm{~N}$ for Beam 1 and Beam 2, respectively. Thus, for the analytical determination of the displacement based on thermal imaging for Beam 1 (Figure 11a), the interface finite temperature along the $X$ direction was obtained as $-0.8^{\circ} \mathrm{C} / \mathrm{mm}^{2}$ and along the $Y$ direction as $-0.9^{\circ} \mathrm{C} / \mathrm{mm}^{2}$. Using Equation 4, the displacement was evaluated as $1.283 \mathrm{~mm}$. In the case of Beam 2 (Figure 11b), the finite temperature along the $X$ direction was obtained as $-0.1^{\circ} \mathrm{C} / \mathrm{mm}^{2}$, along the $Y$ direction as $-0.2^{\circ} \mathrm{C} / \mathrm{mm}^{2}$ and the displacement was obtained as $1.641 \mathrm{~mm}$.

On the other hand, the accelerometer measured analysis indicates Beam 1 oscillated at $40.0802 \mathrm{~Hz}$ (Figure 13a) while Beam 2 did so at $20.0401 \mathrm{~Hz}$ (Figure 13b). Compared with IRT measured frequencies, the relative differences were $0.28 \%$ and $0.20 \%$ for the former and latter (Figure 12), respectively. Similarly, the displacement acquired from the analysis thermal imaging agreed well with the mean displacements acquired using the miniature Deltatron accelerometer (Table 5), with relative differences being $13.15 \%$ and $14.88 \%$ for Beam 1 and Beam 2 , respectively.

\section{Conclusion}

In this paper, an extensive comparative study using IRT and miniature Deltatron accelerometer sensors in measuring structural vibration characteristics in terms of frequency and displacement based on beam-like structures was carried out. For all cases considered, the relative difference exhibited in frequency and displacement were $0.28 \%$ and $14.88 \%$, respectively. The good agreement exhibited in frequencies measured by both IRT and the accelerometer is evidence of the suitability of IRT for

Table 4: Displacement statistics (both beams excited at $20 \mathrm{~Hz}$ ).

\begin{tabular}{lcccc} 
& \multicolumn{2}{c}{ Beam 1 } & \multicolumn{2}{c}{ Beam 2 } \\
\cline { 2 - 3 } \cline { 5 - 5 } Description & Disp. $(\mathrm{mm})$ & Exciter force $(N)$ & & Disp. $(\mathrm{mm})$ \\
Mean & 1.186 & 2.50 & 1.016 & 3.51 \\
Max & 2.120 & 4.94 & 2.043 & 8.49 \\
Min & 0.009 & 0.14 & 0.002 & 0.01 \\
Range & 2.11 & 4.80 & 2.041 & 8.48 \\
Std. deviation & 0.582 & 1.37 & 0.613 & 2.35
\end{tabular}



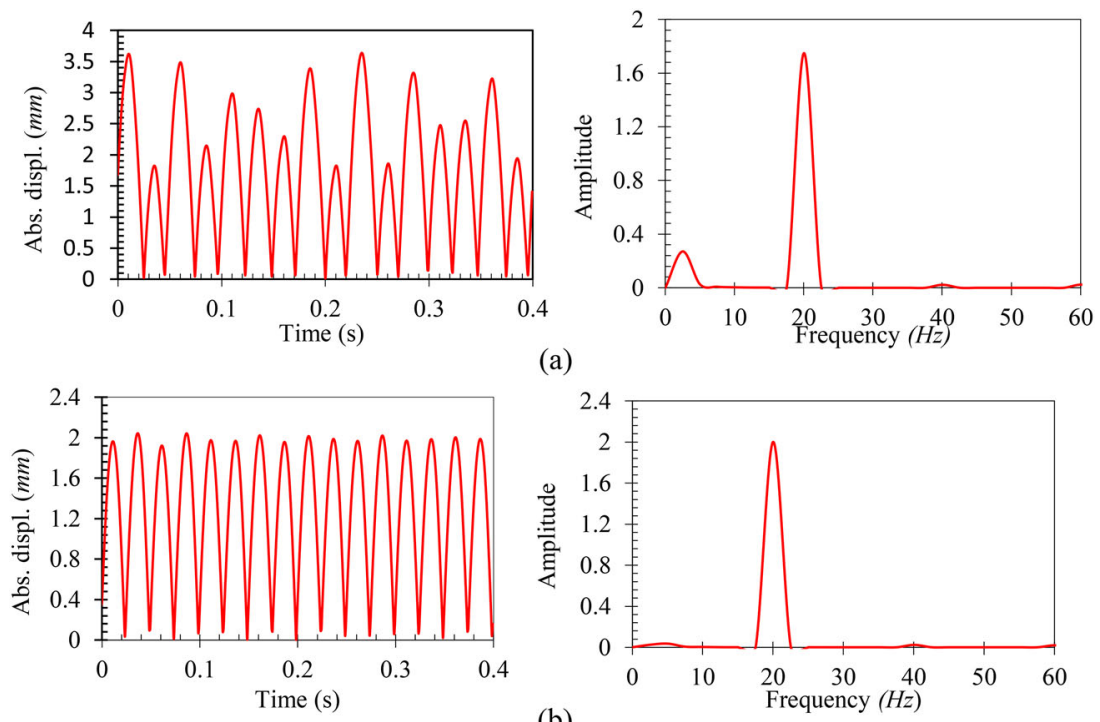

(b)

Figure 10: Displacement time domain and FFT for both beams excited at $20 \mathrm{~Hz}$ (a) Beam 1 and (b) Beam 2.

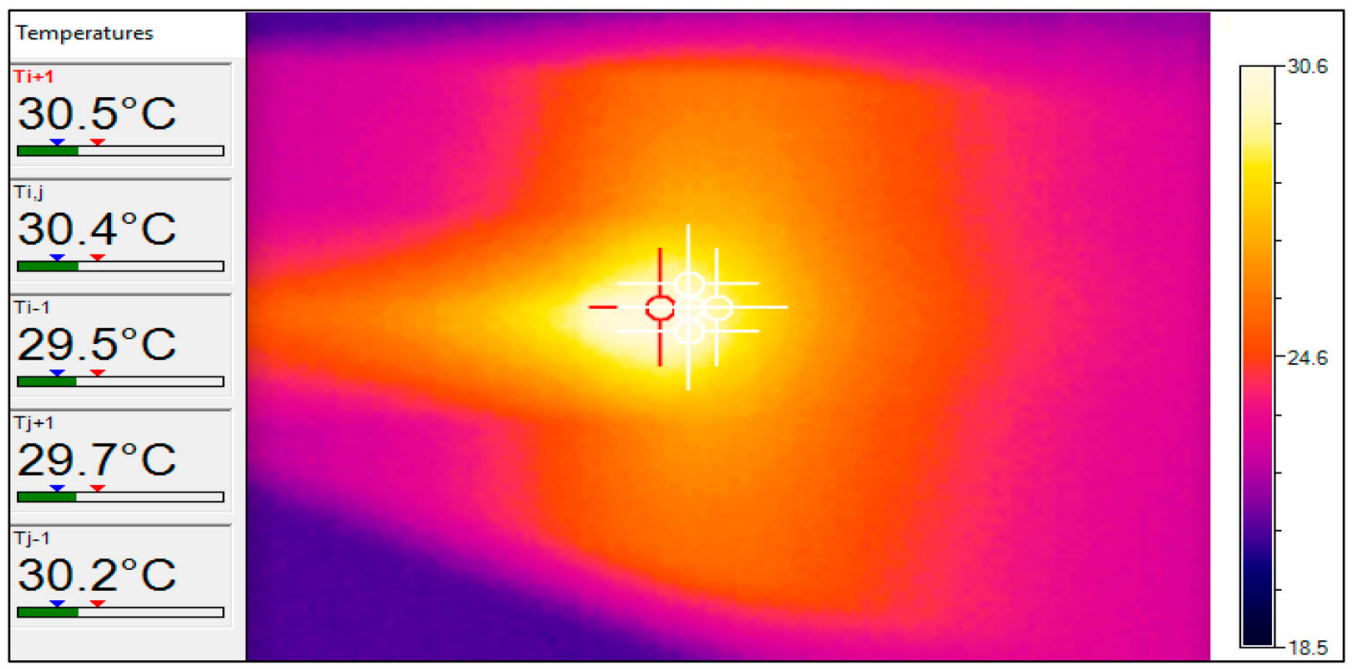

(a)

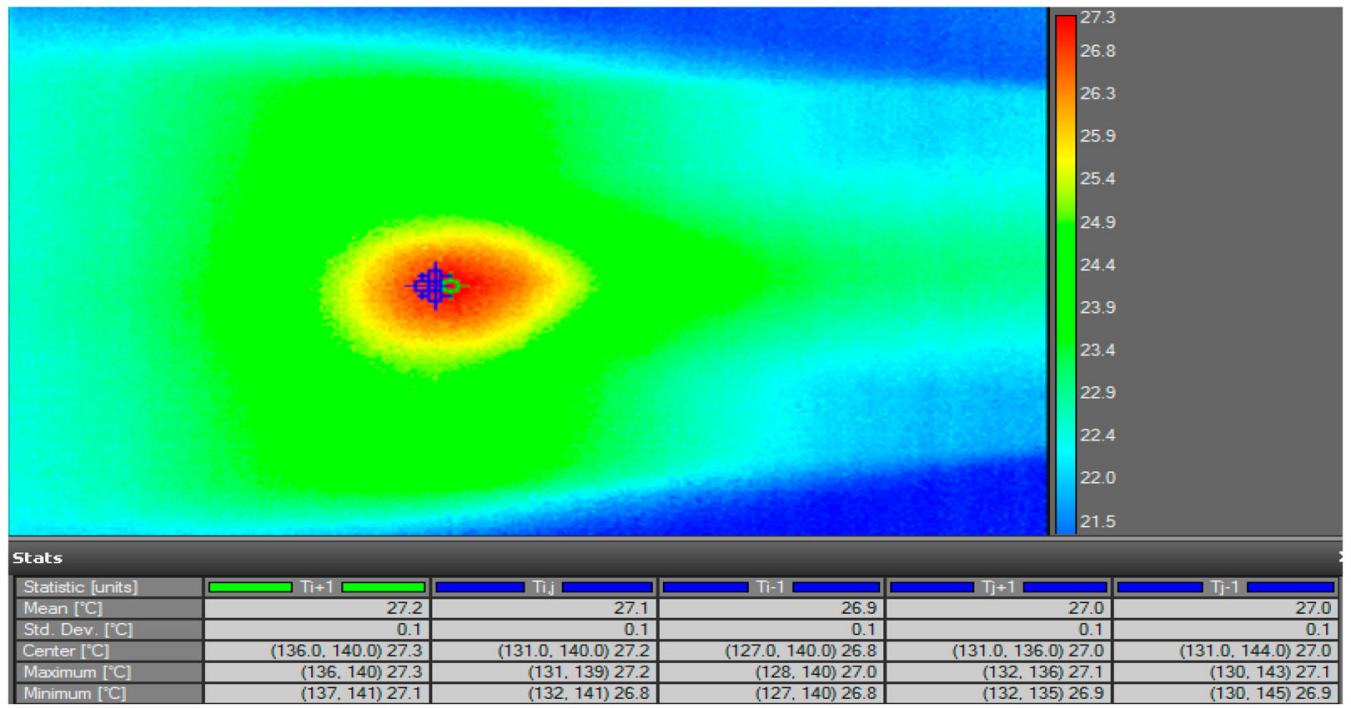

(b)

Figure 11. Thermal imaging after $150 \mathrm{~s}$ for (a) Beam 1 at $40 \mathrm{~Hz}$ and (b) Beam 2 at $20 \mathrm{~Hz}$. 


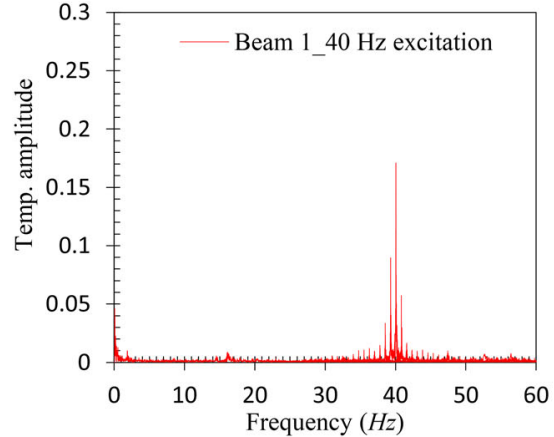

(a)

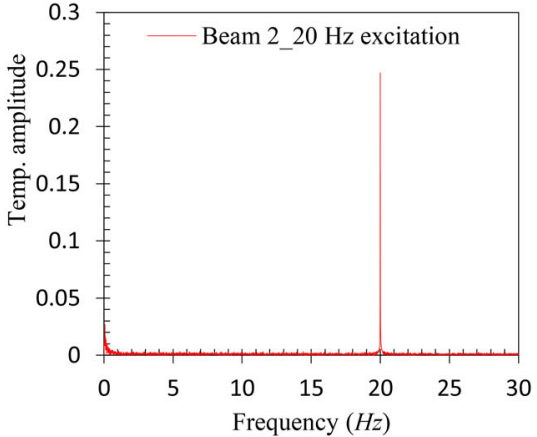

(b)

Figure 12. FFT of temperature evolution (a) Beam 1 at $40 \mathrm{~Hz}$ and (b) Beam 2 at $20 \mathrm{~Hz}$.

Table 5: Displacement and interface force statistics (Beam 1: $40 \mathrm{~Hz}$ and Beam 2: $20 \mathrm{~Hz}$ ).

\begin{tabular}{|c|c|c|c|c|}
\hline \multirow[b]{2}{*}{ Description } & \multicolumn{2}{|c|}{ Beam 1: $40 \mathrm{~Hz}$} & \multicolumn{2}{|c|}{ Beam 2: $20 \mathrm{~Hz}$} \\
\hline & Disp. (mm) & Exciter force $(N)$ & Disp. (mm) & Exciter force $(N)$ \\
\hline$\overline{\text { Mean }}$ & 1.114 & 5.52 & 1.397 & 3.19 \\
\hline Max & 1.616 & 12.33 & 2.308 & 7.21 \\
\hline Min & 0.004 & 0.00 & 0.006 & 0.00 \\
\hline Range & 1.612 & 12.32 & 2.302 & 7.21 \\
\hline Std. deviation & 0.450 & 3.52 & 0.598 & 1.85 \\
\hline
\end{tabular}
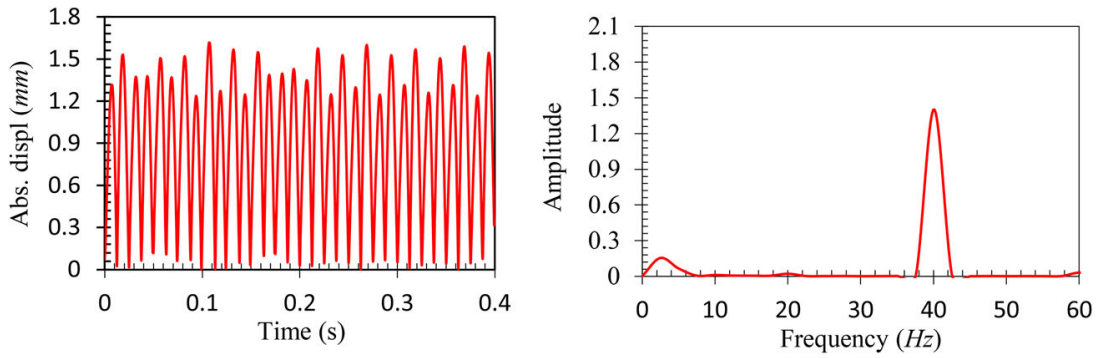

(a)
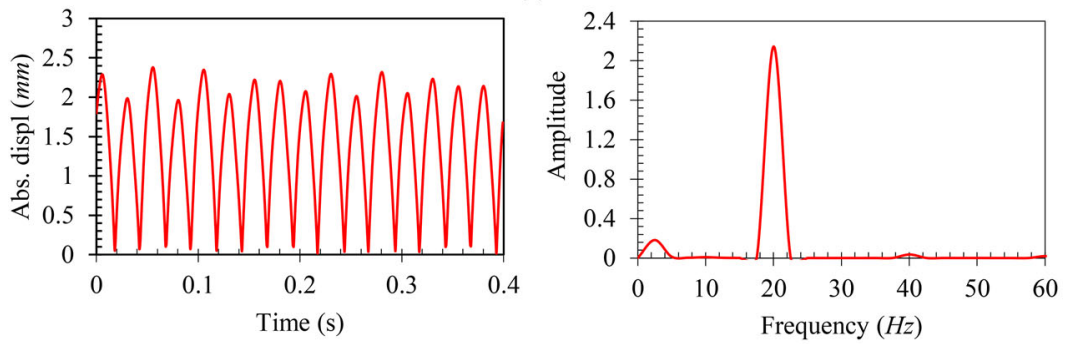

(b)

Figure 13. Displacement time domain and FFT for (a) Beam 1: $40 \mathrm{~Hz}$ and (b) Beam 2: $20 \mathrm{~Hz}$.

online structural integrity maintenance in terms of vibration frequency. Since the prediction of displacement from thermal imaging is dependent on the friction coefficient and the convective heat coefficient, which are nonlinear in nature, the use of IRT in this case is not as reliable as the use of an accelerometer. The findings of this study have great significance for the mechanical and aerospace engineering communities in the use of infrared thermography for effective online monitoring of the structural health of dynamic structures with frequency as an indicator of health. Such monitoring can reduce both downtime and maintenance costs, leading to increased efficiency.

\section{Disclosure statement}

No potential conflict of interest was reported by the authors.

\section{Funding}

The authors greatly appreciate the support of the Eskom Power Plant Engineering Institute (Republic of South Africa), the University of Pretoria and the Tshwane University of Technology for funding this research. 


\section{References}

Al-Bedoor, B. O. 2002. "Discussion of the Available Methods for Blade Vibration Measurement." ASME 2002 pressure vessels and piping conference, Vancouver, BC: Canada. 1561:53-61.

Bagavathiappan, S., B. B. Lahiri, T. Saravanan, J. Philip, and T. Jayakumar. 2013. "Infrared Thermography for Condition Monitoring - A Review." Infrared Physics \& Technology 60: $35-55$.

Brock, N., J. Hayes, B. Kimbrough, J. Millerd, M. North-Morris, M. Novak, and C. J. Wyan. 2005. "Dynamic Interferometry." Proceedings of SPIE, 5875.

Castellini, P., M. Martarelli, and E. P. Tomasini. 2006. "Laser Doppler Vibrometry: Development of Advanced Solutions Answering to Technology's Needs." Mechanical Systems and Signal Processing 20: 1265-1285.

Dimarogonas, A. D., S. A. Paipetis, and T. G. Chondros. 2013. Analytical Methods in Rotor Dynamics. 2nd ed., 203-263. New York, London: Springer Dordrecht Heidelberg. Guran,

A., F. Pfeiffer, and K. Popp. 2001. "Dynamics with Friction Modelling, Analysis and Experiments." World Scientific: Singapore, 7: 20-21.

Lahiri, B. B., S. Bagavathiappan, C. C. Soumya, V. Mahendran, V. P. M. Pillai, J. Philip, and T. Jayakumar. 2014. "Infrared Thermography Based Defect Detection in Ferromagnetic Specimens Using a low Frequency Alternating Magnetic Field." Infrared Physics \& Technology 64: 125-133.

Le, T. T. H., N. Point, P. Argoul, and G. Cumunel. 2016. "Structural Changes Assessment in Axial Stressed Beams Through Frequencies Variation." International Journal of Mechanical Sciences 110: 41-52.

Mabrouki, F., M. Thomas, M. Genest, and A. Fahr. 2009. "Frictional Heating Model for Efficient use of Vibrothermography." NDT \& E International 42 (5): 345-352.
Madhusudana, C. V. 1999. "Thermal Conductance of Cylindrical Joints." International Journal of Heat and Mass Transfer 42: 1273-1287.

Montanini, R., and F. Freni. 2013. "Correlation Between Vibrational Mode Shapes and Viscoelastic Heat Generation in Vibrothermography." NDT \& E International 58: 43-48.

Mukhopadhyay, N. K., S. G. Chowdhury, G. Das, I. Chattoraj, S. K. Das, and D. K. Bhattacharya. 1998. "An Investigation of the Failure of low Pressure Steam Turbine Blades." Engineering Failure Analysis 5 (3): 181-193.

Oden, J. T., and J. A. C. Martins. 1985. "Models and Computational Methods for Dynamic Friction Phenomena." Computer Methods in Applied Mechanics and Engineering 52: 527-634.

Rajput, R. K. 2006. Heat and Mass Transfer, 3 0 -40. Ram Nagar, New Delhi: S. Chard \& Company Ltd.

Rao, S. J. 1991. Turbo-machine Blade Vibration, 1st ed., 7-20. New Delhi: New age international publishers.

Renshaw, J., J. C. Chen, S. D. Holland, and T. R. Bruce. 2011 "The Sources of Heat Generation in Vibrothermography." NDT \& E International 44 (8): 736-739.

Sanders, W. P. 1996. Turbine Steam Path Engineering for Operations and Maintenance Staff, 1st ed., 236-239. Ontario, Canada: Richmond Hill.

Singh, M., and G. Lucas. 2011. Blade Design \& Analysis for Steam Turbines, 20-60. New York: The McGraw-Hill Companies.

Straffelini, G. 2015. Friction and Wear: Methologies for Design and Control, 21-58. Trento: Springer.

Talai, S. M., D. A. Desai, and P. S. Heyns. 2016. "Vibration Characteristics Measurement of Beam-Like Structures Using Infrared Thermography." Infrared Physics \& Technology 79: 17-24. 